\title{
Revista
}

Ropp) Gestão \& Políticas Públicas

Artigo

\section{A Lógica da Governance - Governação/Governança - nas Políticas Públicas de Turismo}

The governance logic in the tourism public policies

La lógica de la Governance - gobernación/gobernanza de las Políticas Públicas de Turismo

Fábio Lourenço', José Manuel Moreira.

${ }^{1}$ Filiação institucional. Mestre em Administração e Gestão Pública (Universidade de Aveiro) e Doutorando em Turismo (Universidade de Aveiro).

Correspondência: $\quad$ E-mail: fabiooalourenco@gmail.com

2 Filiação institucional. Professor Catedrático de Ciências Sociais e Políticas - Universidade de Aveiro e Investigador do CIEP da Universidade Católica Portuguesa

Correspondência: $\quad$ E-mail: jmmoreira1949@gmail.com

Resumo $\quad O$ termo governance adquiriu, desde os anos 90 do século $X X$, particular destaque na discussão teórica e na investigação empírica das ciências sociais. O presente artigo visa o esclarecimento do conceito de governance (governação/governança) e, principalmente, perceber as implicações da lógica da governance nas políticas públicas de turismo: enquadrando-a no movimento de reforma do setor público. De seguida, procede-se à identificação do "estado da arte" sobre a governance no turismo - através da análise de um conjunto de artigos selecionados da base de dados Scopus -, para compreender como nesse âmbito se entende o conceito e de que modo a lógica da governance alterou o papel do Estado nas políticas 
públicas de turismo. Os resultados deste estudo permitem verificar que a distinção entre governação e governança ajuda a melhor compreender os diferentes modos de atuação do Estado, em especial no que concerne às políticas públicas de turismo.

Palavras-chaves: Governance, Governança; Governação; Políticas Públicas de Turismo; Reforma do Sector Público.

Abstract Since the 1990's, the word governance was particularly highlighted in the theoretical discussion and empirical investigation of social sciences. The current paper aims to clarify the governance concept and, mainly, understand the effects of the governance logic in the tourism public policies: contextualizing this logic in the public sector reform movement. Following, one proceeds to identify the "state of art" of governance in tourism - through the analysis of a set of articles selected from the Scopus database -, in order to understand how the concept is perceived and how the governance logic altered the State's role in the tourism public policies. The results of this study allow us to understand how the distinction between governação and governança helps to explain the State's different ways of acting, especially concerning tourism public policies.

Keywords: Governance; Tourism Public Policies; Public Sector Reform.

Resumen El término governance adquirido de los años 90 del siglo XX, haciendo especial hincapié en la discusión teórica y la investigación empírica en las ciencias sociales. Este artículo tiene por objeto aclarar el concepto de governance (gobernación / gobernanza), y sobre todo para entender las implicaciones de la lógica de la gobernanza en las políticas turísticas públicas: enmarcándolo en el movimiento de reforma del sector público. A continuación, proceder a la identificación del "estado del arte" en la governance del turismo - a través del análisis de un conjunto de elementos seleccionados de la base de datos Scopus - para entender cómo en este contexto se entiende el concepto y la forma de la lógica de gobierno cambió el papel del Estado en las políticas públicas de turismo. Los resultados de este estudio nos permiten verificar que la distinción entre la 
gobernación y la gobernanza ayuda a comprender mejor las diferentes modalidades de la acción del Estado, especialmente con respecto a las políticas públicas del turismo.

Palabras Clave: Gobernabilidad; La Gobernanza; La Política Pública; El Turismo; La Reforma del Sector Público. 


\section{Introdução}

O conceito de governance adquiriu, a partir de finais do séc. $\mathrm{XX}$, particular destaque no debate teórico das ciências sociais e políticas. Passando a ser uma das principais temáticas de estudo, ainda que a sua ampla utilização se debata com entendimentos e empregos diversos do conceito. Mas foi só no séc. XXI, que, graças aos contributos da ciência política, emergiu de forma significativa a investigação da governance no turismo. O presente estudo visa perceber a evolução do conceito de governance e dar conta da relevância da distinção entre governança e governação enquadradas no movimento de reforma do sector público tendo em vista uma melhor apreciação da atuação do Estado no âmbito das políticas públicas do turismo.

$\mathrm{O}$ artigo estrutura-se em três grandes momentos. No primeiro, analisar-seá o conceito de governance a partir dos contributos da ciência política e sua influência para o debate. Tendo em vista esclarecer o conceito e identificar pistas a explorar na análise da governance no turismo. No segundo, procurar-se-á identificar o "estado da arte" da investigação da governance no turismo, principalmente nas políticas públicas de turismo, através da revisão de literatura de um conjunto de artigos científicos selecionados da base de dados Scopus. No terceiro, proceder-se-á a um conjunto de reflexões relativas ao conteúdo dos artigos analisados sobre a governance (governação/governança) no turismo discutindo os resultados e as limitações dos estudos e apontando possíveis linhas de investigação a explorar no futuro.

\section{Governance}

\subsection{Governo, governação e governança}

A recente popularidade do conceito governance parece advir da sua capacidade - ao contrário da palavra government (governo) - para contemplar a diversidade de instituições e relações presentes no processo governativo (Pierre $\&$ Peters, 2000).

Percebe-se, por isso, que governance tenha vindo a destronar a sua palavra parente: governo. Do ponto de vista etimológico, ambas derivam do verbo grego kubernan, que representa dirigir uma embarcação - o significado está relacionado com uma metáfora utilizada por Platão na República, que assemelha o governo de uma polis à navegação de uma embarcação. Do termo grego derivou o verbo latino gubernare, que deu origem ao francês gouverner, e este terá passado para outras línguas, como o inglês e o português. Este desenvolvimento aconteceu sem uma clara diferenciação entre os dois nomes 
gémeos, governance e governo, embora o primeiro fosse menos utilizado. Todavia, desde os anos 90 do século XX, esta situação alterou-se, quando a palavra governance conquistou um novo significado e uma nova oportunidade de vida - graças à sua utilização em inglês. O relatório Governance and Development, do World Bank (1992), que definiu governance como "a forma como o poder é exercido na gestão dos recursos económicos e sociais para o desenvolvimento", veio dar um novo fulgor ao termo. O mesmo relatório sugere que a good governance é um pressuposto essencial para o desenvolvimento sustentável (Plattner, 2013).

Importa, aqui, fazer um ponto de ordem para, na linha de Andra I. Milcu (apud Plattner, 2013), manter a distinção entre governo e governance. Considerando a governance "como uma forma de gestão do poder e da política e o governo seria um instrumento para o fazer". O que permitiria ver a governance "como uma alternativa ao convencional controlo, de cima para baixo, exercido pelo governo". Alternativa que para Moreira (2014, p. 45) tenderia a ser reduzida a novos modos, mesmo que mais partilhados, de atingir os mesmos fins, ainda que de forma mais duradoura e equilibrada. Descurando que, na tal "alternativa ao convencional controlo de cima para baixo", se terá de admitir duas vias de relacionamento do governo com a sociedade civil e os mecanismos de mercado. Uma, mais "managerial" ou instrumental, virada para o cumprimento de objetivos ou fins concretos, mesmo que de modo mais participado, afastando-se assim da forma autoritária de "mando e controlo". E outra, mais cívico-política, centrada na lisura dos meios, no primado de valores abstratos. Justificando a distinção entre "governança" e "governação". Na primeira, a autoridade continuaria a basear-se, embora de forma mais branda e democrática, em "ordens" ou diretrizes a cumprir, ainda que atendendo aos interesses dos cidadãos e fazendo uso de mecanismos de mercado. Já na segunda a autoridade assentaria no primado do Direito, não da legislação. Ou seja, no respeito pelas regras de jogo, sem condescendência por quaisquer formas de hedonismo político, e, por isso, sem propensão à corrupção da sociedade civil por parte do Estado.

Distinção que, ainda segundo Moreira (2014, p. 45), é idêntica à de Hayek entre "nomocracia", que se apoia em normas gerais (nomoi), e "teleocracia", organização dirigida a objetivos particulares (taxis). O que nos conduz a duas conceções de "interesse público": uma, em que o público se ajusta ao comum, implicando respeito pela diversidade de entendimentos do "público". Daí a ênfase na liberdade de escolha nos vários âmbitos do humano. Outra, entendida como somatório utilitarista de interesses particulares, ainda que avalizado por legislação votada por maiorias democráticas. De que resultam dois papéis do Governo. Um em que se obriga a objetivos, como, por exemplo, o pleno emprego ou desenvolvimento económico. E outro em que o que importa não é a intervenção ou direção da sociedade, mas tão só a promoção, proteção e defesa de um ambiente propício a uma vida económica verdadeiramente livre que 
favoreça a iniciativa e criatividade humana num clima de coordenação frutuosa ou, como diria Adam Smith, harmoniosa.

\subsection{Enquadramento da governance no movimento de reforma do}

\section{sector público}

Antes de se discutir a governance - governação/governança - no turismo é proveitoso enquadrá-la no movimento de reforma do sector público, pois ajudará a esclarecer o uso do termo para descrever as mudanças ocorridas na década de 90 do século XX.

Embora ao longo do tempo, o sector público tenha sofrido transformações nos seus vários domínios para se ajustar a novas exigências, o movimento de reforma não é uniforme em todo o mundo. Até pela influência dos contextos específicos de cada país. Todavia, apesar dessas especificidades, pode-se descortinar semelhanças nas lógicas de reforma do sector público, como acontece, por exemplo, com os países ocidentais.

De acordo com Moreira e Alves (2010, p. 46), para se entender o movimento de reforma do sector público é útil recorrer-se a três lógicas que o acompanham: a da Administração Pública Tradicional, orientada para a legislação; a da Nova Gestão Pública, orientada para o serviço; e, por fim, a da Governação Pública, orientada para os cidadãos. Os mesmos autores alertam, contudo, que estas três lógicas não devem ser tidas como "fases" sucessivas, mas "como três vertentes orientadoras que podem co-existir umas com as outras em algum grau em uma qualquer agência".

\subsubsection{Administração pública tradicional (APT)}

A APT é bastante influenciada pelos princípios do modelo de organização de Max Weber, devido a este ter realizado uma investigação sobre a Burocracia, na qual estudou o modelo tradicional - ou modelo burocrático - de Administração Pública.

Um conjunto de críticas relevantes tem sido apontadas à APT:

i. o excessivo foco no cumprimento das regras e procedimentos leva a que a Administração Pública seja em grande parte indiferente às vontades dos cidadãos e não tenha em conta os resultados (Moreira \& Alves, 2010; Peters, 2008); 
ii. o modelo hierárquico diminui a capacidade de resposta e aumenta os custos de funcionamento devido a todas as tomadas decisões necessitarem de passar pelos níveis superiores da hierarquia (Hughes, 2003);

iii. os funcionários públicos tendem, por vezes, a maximizar o orçamento discricionário ao seu dispor e a dimensão das organizações públicas, sem que daí resulte uma melhoria do serviço prestado (Alves \& Moreira, 2004);

iv. o Estado demasiado "centralista" - top-down - e com estruturas "monopolistas" de prestação de serviços, que definem quais os tipos e os modos de prestação de serviço, sem uma efetiva preocupação com as reais necessidades dos cidadãos (Stoker, 2008).

Apesar destas críticas, há que referir que a APT constituiu num grande avanço em relação ao passado, uma vez que, ao instituir determinadas normas e procedimentos, contribuiu para combater o nepotismo e arbitrariedade no tratamento dos cidadãos (Hughes, 2003).

\subsubsection{Nova gestão pública (NGP)}

A NGP privilegia o desempenho, promove a responsabilização e a competição, apostando na qualidade e na desagregação das tradicionais unidades de trabalho (Hood, 1995; Hood \& Peters, 2004). Este movimento é caracterizado pela introdução de técnicas da gestão privada no sector público, com foco na prestação de serviço e na orientação para o cliente (Bovaird \& Löffler, 2003; Kickert, 2002; Pollitt, 2009).

Embora se reconheça os méritos na promoção da eficiência, eficácia e economia, a NGP é alvo de um conjunto de críticas, de que se destaca:

i. o uso exagerado da avaliação de desempenho com base nos outputs pode gerar efeitos perversos pois, ao centrar-se nos fins/objetivos, pode negligenciar os meios utilizados para os atingir (Le Grand, 2010; Moreira \& Alves, 2010);

ii. o poder hierárquico fortemente centralizado continua a persistir na prática, apesar da NGP anunciar a descentralização e a delegação de competências (Madureira \& Rodrigues, 2006); 
iii. certas técnicas da gestão empresarial são desadequadas ao sector público, devido à multiplicidade das organizações públicas e das suas especificidades (Hughes, 2003; Kickert, 1997; Stoker, 2008).

\subsubsection{Governação pública (GP)}

A partir de meados dos anos 90, surgiu uma nova forma de olhar para a "coisa pública", designada por Governação Pública ou, recorrendo à designação de Stoker, Gestão do Valor Público (Moreira \& Alves, 2010; O'Flynn, 2007; Stoker, 2008).

De acordo com Stoker (2008), este paradigma de gestão é norteado pelo princípio da promoção do valor público, respeitando, ao contrário da NGP, as especificidades do sector público. Para Stoker (2008, p. 32), tal lógica de gestão é baseada na ideia de que "o valor público é mais do que uma soma das preferências individuais dos utentes ou dos fornecedores de serviços públicos", pois o "valor público é construído colectivamente por meio da discussão e da deliberação, envolvendo membros eleitos e não eleitos das estruturas de governo e outros actores-chave". Daí que o autor realce a motivação das pessoas para participarem em parcerias e redes cívicas em busca de objetivos comuns (Stoker, 1998).

Segundo Moreira e Alves (2010), esta lógica tem um enfoque mais direcionado para as pessoas e a sociedade civil e não tanto para o Estado, vincando o primado das regras e o reforço da ligação entre a criação de valor e o estímulo para os cidadãos desenvolverem as suas capacidades.

Bovaird e Löffler (2003) defendem que os autores que estudaram a GP tendem a concordar com os seguintes elementos para a caracterizar:

i. as autoridades públicas deixam de atuar isoladamente na resolução dos problemas coletivos, estabelecendo processos de cooperação com outros atores (cidadãos, sectores privado e voluntário) admitindo-se que a ação pública em certos casos possa ser mais eficaz se o seu papel passar pela mediação, arbitragem e autorregulação;

ii. tem em conta regras formais (constituições, leis e regulamentos) e regras informais (códigos éticos, costumes e tradições) - no entanto, reconhece, que a importância das últimas regras pode ser alterada pelos stakeholders (devido ao uso do seu poder) durante o processo de negociação; 
iii. o mercado deixa de ser o único mecanismo de orientação (como na Nova Gestão Pública), concedendo-se que as hierarquias (como na Administração Pública Tradicional) e as redes de cooperação podem desempenhar um papel relevante em determinadas circunstâncias;

iv. não se centra somente na lógica dos meios e fins, inputs e outputs, mas também contempla outros elementos valorizados nos processos fundamentais da interação social - entre outros, a transparência, a integridade e a honestidade;

v. é inerentemente política: na medida em que os stakeholders, ao procurarem exercer o poder uns sobre os outros na busca dos seus interesses, acentuam a tensão entre os «de cima»e os «de baixo», questionando assim a entrega da «coisa pública» às elites dos gestores públicos ou dos profissionais da tomada de decisão.

Acresce que, apesar dos reconhecidos méritos, há interrogações e desafios à GP quanto à concretização dos seus princípios:

i. a dúvida se a GP é um conceito positivo ou normativo, uma vez que na maioria das suas definições há princípios de "boa governação" (entre outros, transparência, sustentabilidade, envolvimento dos stakeholders e responsabilidade), que enunciam aspetos normativos do conceito (Bovaird, 2005);

ii. a má aplicação dos princípios da GP pode, por vezes, reduzir a eficiência das operações do sector público - por exemplo, o compromisso de envolver todos os stakeholders poderá levar à fragilização das regras do jogo, provocando custos e atrasos consideráveis na tomada de decisão e implementação de medidas governativas (Bovaird, 2005);

iii. a participação de múltiplos stakeholders nas políticas públicas pode diminuir a accountability, pois fragmenta a responsabilização dos atores envolvidos (Bovaird, 2005; Stoker, 2008);

iv. a participação dos cidadãos no processo político pode ser condicionada por limitações sociais e económicas, ainda que os cidadãos possam optar pela não participação por entenderem que os seus interesses estão assegurados ou não se encontram ameaçados (Stoker, 2008). 
Tabela 1 - Síntese dos três paradigmas

\begin{tabular}{|c|c|c|c|}
\hline & APT & NGP & GP \\
\hline $\begin{array}{l}\text { Chave } \\
\text { Pública }\end{array}$ & A legislação & O serviço & O cidadão \\
\hline $\begin{array}{l}\text { Objetivo } \\
\text { dos } \\
\text { Gestores }\end{array}$ & $\begin{array}{l}\text { Conformidade legal } \\
\text { assegurada por } \\
\text { cumprimento de } \\
\text { regras e } \\
\text { procedimentos }\end{array}$ & $\begin{array}{l}\text { Definição de meios } \\
\text { competitivos para } \\
\text { cumprir objetivos que } \\
\text { implicarão avaliação }\end{array}$ & $\begin{array}{c}\text { Qualidade de vida, } \\
\text { autonomia dos cidadãos, } \\
\text { diversidade organizacional } \\
\text { e escolha entre } \\
\text { alternativas }\end{array}$ \\
\hline $\begin{array}{l}\text { Perspetiv } \\
\text { a }\end{array}$ & Estado & Sector Público & Sociedade Civil \\
\hline $\begin{array}{l}\text { Mecanism } \\
\text { o de } \\
\text { Controlo }\end{array}$ & Hierárquico & Mercado & Parcerias e redes cívicas \\
\hline Lógica & Jurídico-legal & $\begin{array}{l}\text { Económica com base } \\
\text { em incentivos e } \\
\text { resultados }\end{array}$ & $\begin{array}{c}\text { Cívica (reconhece os } \\
\text { limites das lógicas Jurídico- } \\
\text { legal e Económica), } \\
\text { incentivando várias formas } \\
\text { de participação ativa }\end{array}$ \\
\hline $\begin{array}{l}\text { Ethos } \\
\text { Público }\end{array}$ & $\begin{array}{l}\text { Monopólio do sector } \\
\text { público }\end{array}$ & $\begin{array}{l}\text { O monopólio leva a } \\
\quad \text { ineficiência? } \\
\text { Ênfase no serviço ao } \\
\text { cliente/consumidor. }\end{array}$ & $\begin{array}{l}\text { Valores partilhados e } \\
\text { alinhamento entre } \\
\text { pluralismo e coopetição }\end{array}$ \\
\hline
\end{tabular}

Fonte: Adaptado de Moreira e Alves (2010).

A Tabela 1 ajuda a distinguir, clarificar e sintetizar os três paradigmas. Ainda que a opção por "governação" (versus governança) no cimo da terceira coluna não signifique que no relacionamento do Estado/Governo com o mercado e a sociedade civil não se tenha de admitir o risco de instrumentalização, mesmo quando se louva a participação pública no processo político. O que nos conduziria a um modo de olhar para a "coisa pública" mais próximo da governança.

\section{A governance - governação/governança - no turismo}

\subsection{Metodologia}

Assim, é possível perceber que as mudanças na contabilidade governamental tendem a uma melhor avaliação dos impactos das políticas públicas e da gestão no que diz respeito às questões fiscais, econômicas e sociais relacionados às variações do patrimônio público.

Tendo em vista conseguir uma percepção global da discussão da governance no turismo, selecionou-se um conjunto de artigos da base de dados 
Scopus. A pesquisa foi realizada em Junho de 2014, utilizando os termos-chave "tourism", "governance" e "public policy". Foram contemplados apenas artigos científicos da área das ciências sociais e humanas, publicados desde o ano de 1990 até ao presente: período temporal coincidente com o crescente destaque da governance. Dessa seleção resultaram 40 artigos: com a larga maioria (36) publicada na última década. As revistas científicas com mais artigos são o Journal of Sustainable Tourism (8 artigos) e o Tourism Management (4 artigos); quanto à filiação dos autores, a Southern Cross University, a Oulun Yliopisto, a University of Twente e a University of Exeter são as mais representadas, com 2 artigos cada. No que se refere a países, destaca-se Reino Unido com 9 artigos, seguido da Holanda, Estados Unidos da América, Canada, Itália, Nova Zelândia e Austrália, com 3 artigos cada. Numa segunda leitura dos 40 artigos constatou-se, todavia, que nem todos os artigos correspondiam aos desígnios do trabalho, levando a que o conjunto fosse reduzido a 18.

Resta acrescentar que seleção final obedeceu à divisão em duas categorias: artigos conceptuais e artigos empíricos. Os conceptuais correspondem aos que discutem fundamentalmente do ponto de vista teórico o conceito de governance e as implicações do mesmo no turismo. Os empíricos consistem em artigos que investigaram empiricamente as referidas implicações da governance no turismo. Todavia, é importante frisar que os artigos considerados empíricos, embora não seja o seu principal objetivo, acrescentam também contributos assinaláveis para o debate teórico do conceito de governance no turismo. A Tabela 2 sintetiza os temas e tipo de estudo dos artigos analisados.

Tabela 2 - Síntese dos artigos analisados

\begin{tabular}{|c|l|}
\hline Artigo & \multicolumn{1}{|c|}{ Tema } \\
\hline $\begin{array}{c}\text { (Andersson \& } \\
\text { Getz, 2009) }\end{array}$ & $\begin{array}{l}\text { Investiga como a natureza da propriedade e a governance } \\
\text { influenciam a gestão de festivais sem fins lucrativos* }\end{array}$ \\
\hline $\begin{array}{c}\text { (Beaumont \& } \\
\text { Dredge, 2010) }\end{array}$ & $\begin{array}{l}\text { Salienta as vantagens e desvantagens das diferentes } \\
\text { abordagens sobre a governance local e reflete a sua relevância } \\
\text { para a gestão sustentável do turismo* }\end{array}$ \\
\hline (Hall, 1999) & $\begin{array}{l}\text { Analisa as implicações da reforma do estado a partir da década } \\
\text { de 70 do século XX no sector do turismo** }\end{array}$ \\
\hline (Hall, 2011a) & $\begin{array}{l}\text { Reflexão teórica sobre relevância da governance na promoção } \\
\text { do turismo sustentável** }\end{array}$ \\
\hline (Hall, 2011b) & $\begin{array}{l}\text { Revisão de literatura sobre governance com a identificação de } \\
\text { 4 tipologias de governance** }\end{array}$ \\
\hline $\begin{array}{c}\text { (Caffyn \& } \\
\text { Jobbins, 2003) }\end{array}$ & $\begin{array}{l}\text { Considera as implicações dos sistemas de governance de } \\
\text { Marrocos e da Tunísia na gestão do turismo costeiro* }\end{array}$ \\
\hline (Dinica, 2006) & $\begin{array}{l}\text { Discute a importância da abordagem política para promover o } \\
\text { desenvolvimento sustentável do turismo e lazer na Holanda* }\end{array}$ \\
\hline (Dinica, 2009) & $\begin{array}{l}\text { Analisa o papel das autoridades públicas na governance do } \\
\text { turismo para a promoção do desenvolvimento sustentável na }\end{array}$ \\
\hline \hline
\end{tabular}




\begin{tabular}{|c|c|}
\hline & Holanda* \\
\hline (Dredge, 2006) & $\begin{array}{l}\text { Através de um estudo de caso, procura compreender como as } \\
\text { redes podem estimular (ou impedir) a formação de parcerias } \\
\text { público-privadas a nível local* }\end{array}$ \\
\hline $\begin{array}{l}\text { (Dredge \& } \\
\text { Whitford, } \\
\text { 2011) }\end{array}$ & $\begin{array}{l}\text { Aborda a governance como uma nova forma de formulação de } \\
\text { políticas público-privadas, analisando como os stakeholders } \\
\text { fazem parte da discussão e atuam para atingir objetivos } \\
\text { comuns* }\end{array}$ \\
\hline $\begin{array}{l}\text { (Erkuş-Öztürk } \\
\text { \& Eraydın, } \\
\text { 2010) }\end{array}$ & $\begin{array}{l}\text { Analisa em conjunto a literatura sobre as redes de governance } \\
\text { e sobre o desenvolvimento sustentável* }\end{array}$ \\
\hline $\begin{array}{l}\text { (Göymen, } \\
\text { 2000) }\end{array}$ & $\begin{array}{l}\text { Relaciona o desenvolvimento do turismo na Turquia com as } \\
\text { dinâmicas de governance** }\end{array}$ \\
\hline $\begin{array}{l}\text { (Ruhanen, } \\
\text { Scott, Ritchie, } \\
\text { \& Tkaczynski, } \\
\text { 2010) }\end{array}$ & Revisão e síntese de literatura sobre a governance** \\
\hline $\begin{array}{l}\text { (Sofield \& Li, } \\
\text { 2011) }\end{array}$ & $\begin{array}{l}\text { Explora a questão da governance e planeamento para a } \\
\text { promoção de um desenvolvimento sustentável à escala } \\
\text { nacional (o caso da China)** }\end{array}$ \\
\hline $\begin{array}{l}\text { (Vernon, } \\
\text { Essex, Pinder, } \\
\text { \& Curry, 2005) }\end{array}$ & $\begin{array}{l}\text { Avalia criticamente a eficácia de abordagens colaborativas no } \\
\text { processo de policymaking (estudo de caso do Council District, } \\
\text { Cornwall, Reino Unido)* }\end{array}$ \\
\hline $\begin{array}{l}\text { (Wang \& Ap, } \\
\text { 2013) }\end{array}$ & $\begin{array}{l}\text { Construção de um framework conceptual para descrever os } \\
\text { fatores que afetam a implementação das políticas públicas de } \\
\text { turismo (framework adaptado ao caso da China)* }\end{array}$ \\
\hline $\begin{array}{c}\text { (Yüksel, } \\
\text { Bramwell, \& } \\
\text { Yüksel, 2005) }\end{array}$ & $\begin{array}{l}\text { Desenvolve um framework para avaliar a descentralização da } \\
\text { governance do turismo (estudo de caso - resort costeiro de } \\
\text { Belek, Turquia)* }\end{array}$ \\
\hline (Zahra, 2011) & $\begin{array}{l}\text { Aborda a problemática da governance nas organizações } \\
\text { regionais de turismo e relaciona-a com o princípio da } \\
\text { subsidiariedade* }\end{array}$ \\
\hline
\end{tabular}

Fonte: Elaboração própria.

\subsection{A Discussão Teórica do Conceito de Governance no Turismo}

No âmbito da investigação o turismo tornou-se recentemente um contexto interessante para se estudar a governance e as suas implicações, revelando um amplo campo de análise onde se cruzam os sectores público e privado e diversos atores da sociedade civil. Cruzamentos que na área do turismo provocam uma multiplicidade de utilizações, definições e dimensões (Ruhanen et al., 2010).

Um dos principais trabalhos na área do turismo que refletiu teoricamente o conceito de governance foi o de Ruhanen et al. (2010), com a realização de uma 
revisão de literatura (53 artigos), que contempla a análise em áreas - como a ciência política e a gestão privada - onde se debate a governance. O estudo identifica 72 dimensões (somente 26 eram partilhadas pela ciência política e gestão privada) utilizadas para caracterizar a governance, com destaque para accountability, transparência, participação, estrutura, eficiência e poder. Esta análise permitiu perceber a dificuldade em criar um corpo teórico crítico sobre a temática devido à natureza multidimensional do conceito.

Um outro trabalho que refletiu densamente o conceito de governance foi o de Michael Hall (2011b), ao apreciar o seu impacto na análise das políticas públicas do turismo. Considerando que, desde os anos 90 do século $X X$, se tem verificado uma mudança gradual na literatura sobre as políticas públicas de turismo: com a alteração da noção de governo para a de governance (entendida como ato de governar). E, recorrendo aos contributos da ciência política, identifica duas formas de a conceber. A primeira - comummente denominada por new governance - é usada para descrever a adaptação contemporânea do Estado aos contextos económico e político. Esta perspectiva centra-se na questão de uma maior participação dos atores privados nos processos governativos e de o papel menos central do Estado. A segunda prende-se com a representação teórica e conceptual do papel do Estado na coordenação do sistema socioeconómico. Admitindo a sua subdivisão em duas categorias de análise: (i) a capacidade do Estado para conduzir o sistema socioeconómico, isto é, a relação do Estado com outros atores políticos, e (ii) a coordenação e selfgovernment, especialmente no que respeita às relações em rede e parcerias público-privadas. Passando depois à identificação de quatro tipologias de governação/governança - hierarquias, comunidades, redes e mercados -, ou, mais concretamente, de quatro formas do Estado se relacionar com a sociedade.

Desenvolvimentos que nos obrigam a regressar à Tabela 1 - síntese dos paradigmas - tendo em vista o aprofundamento e clarificação das duas visões do Estado que, no limite, suportam a distinção entre governança e governação. Vendo o Estado na primeira como fornecedor de bem-estar (Vater Staat, Estado como Pai), e na segunda, como guardião da estrutura no seio da qual os indivíduos se podem prover a si próprios. Justificando-se assim a ligação do termo governação ao (re)surgimento e (re)valorização - ou consolidação - de formas sociais independentes de autorregulação, autogoverno e coordenação social.

Distinção que ajuda a dar outro alcance às três formas de "autonomia social" que, em consonância com Hall, Aguilar Villanueva (2006) considera estarem a acontecer: (i) nos mercados; (ii) nos comportamentos de cooperação, solidariedade e mútua ajuda; (iii) e, mais recentemente, na livre conectividade facilitada pelas tecnologias da informação e da comunicação. O que, segundo o mesmo autor, obriga a distinguir entre: (i) government, instituição responsável do governo de uma sociedade; (ii) governing, o governar entendido aqui como a ação de governar do próprio governo; (iii) governance, como processo mais ou 
menos formalizado de governar(-se) ou conduzir(-se) uma (a) sociedade, tal como ocorre num determinado tempo social e em que o governo é um ator com maior ou menor capacidade de decisão ou influência diretiva. Uma sequência que leva o mesmo Villanueva a afirmar que desenvolvimentos mais recentes que ilustra com o título e a tese do livro de J. Kooiman (2003), Governing as Governance - revelam que o "governar do governo" (governing) é hoje um modo de governance (a que chama governança): transformando o governar moderno num "processo político-social", e não só governamental, que implica o contributo e a coordenação de atores do governo e atores sociais. Numa tensão bem expressa no lema "Menos governo e mais governance", usado na campanha eleitoral por Narendra Modi, primeiro-ministro da Índia.

Precisões que ainda mais reforçam a necessidade de atentar a dois modos distintos de conjugar o atuar do governo com os agentes do mercado e da sociedade civil. Preocupação a que, em parte, o próprio Aguilar Villanueva atende, ainda que de forma polémica, ao dizer que o conceito pode servir de veículo para formular programas de governance without government, que representa, no terreno de uma comunidade política particular, a situação de descentramento do poder que caracteriza as relações internacionais e as relações de mercado. Podendo atingir até o tom retórico e dramático do chamado esvaziamento do Estado (the hollowing out of the state): expresso na ideia de que o papel do governo, na condução da sociedade, perdeu protagonismo e que a sua atividade diretiva é insuficiente (Moreira \& Alves, 2010; Villanueva, 2006).

Outros investigadores do turismo, apesar dos seus trabalhos terem um maior teor empírico, também produziram um conjunto de reflexões sobre a governance - governação/governança. Contributos que, em termos gerais, estão em linha com a dinâmica que levou o Estado a repensar a sua atuação no turismo, promovendo o surgimento de novas formas de cooperação, novos atores, novas estruturas e arranjos institucionais, novas formas de participação, comunicação e accountability (Andersson \& Getz, 2009; Beaumont \& Dredge, 2010; Dinica, 2009; Dredge, 2006; Dredge \& Whitford, 2011; Göymen, 2000; Vernon et al., 2005; Wang \& Ap, 2013; Yüksel et al., 2005; Zahra, 2011).

\subsection{A Governance nas Políticas Públicas de turismo}

O movimento da governance, desde os anos 90 do século $\mathrm{XX}$, contribuiu para a transformação do papel do Estado, provocando um conjunto de alterações na forma como este "olha" e se relaciona com a sociedade e a economia. Mudanças que tiveram também implicações no âmbito do turismo, sobretudo nas 
políticas públicas, que sofreram modificações na forma, no conteúdo, nos processos, nos intervenientes e no próprio financiamento do sector.

Uma das alterações do papel do Estado relativamente ao turismo promovidas pelo movimento da governance traduziu-se em o Estado ter passado a atuar também como coordenador e impulsionador das ações de desenvolvimento do turismo. O que nos remete mais uma vez para enfatização da governação versus governança, ou seja, um Estado mais capaz de estimular a formação de redes e de parcerias público-privadas. Acentuando assim o seu papel de coordenação - vertical e horizontal - de modo a fomentar a cooperação e colaboração num sector fragmentado como é o do turismo. Como resultado, os atores privados e outros stakeholders passaram a participar no processo de decisão e implementação das políticas públicas de turismo. As potencialidades das parcerias e da colaboração dos stakeholders nas políticas públicas de turismo são, entre outras, a minimização dos custos de conflitos, a legitimação de decisões, aumento da eficácia e eficiência, e a facilitação da coordenação e da implementação (Andersson \& Getz, 2009; Beaumont \& Dredge, 2010; Dredge, 2006; Dredge \& Whitford, 2011; Erkuş-Öztürk \& Eraydın, 2010; Göymen, 2000; Vernon et al., 2005; Wang \& Ap, 2013; Zahra, 2011). É, no entanto, importante referir que a coordenação é um processo difícil de concretizar, uma vez que envolve organizações diferentes - privadas e públicas -, com múltiplos objetivos - não raras vezes, díspares e conflituantes - e com desiguais níveis de poder e de recursos (Hall, 1999; Vernon et al., 2005; Zahra, 2011). Além disso, estas práticas da governance variam de país para país, cada um com a sua conjuntura, determinante para a (não)promoção de parcerias e processos colaborativos nas políticas públicas de turismo (Andersson \& Getz, 2009; Dredge \& Whitford, 2011; Göymen, 2000; Wang \& Ap, 2013).

Uma outra característica do movimento da governance no turismo é a valorização de uma abordagem bottom-up e descentralizadora das políticas públicas, que estimule a participação e a inclusão dos atores locais no processo formulação, decisão e implementação das mesmas. Por contraposição a um modelo impositivo de políticas públicas (top-down), característico de um Estado centralizado que assumia inteiramente as responsabilidades pelas políticas públicas de turismo. Defendendo-se a promoção da participação dos atores locais e dos cidadãos no debate das políticas públicas de turismo como condição para o aumento da transparência, legitimação, confiança e accountability dos processos governativos (Beaumont \& Dredge, 2010; Caffyn \& Jobbins, 2003; Göymen, 2000; Vernon et al., 2005; Wang \& Ap, 2013; Yüksel et al., 2005; Zahra, 2011). Mesmo que se admita que a descentralização do poder pode conduzir a tensões entre os governos centrais e locais, geradas, por exemplo, pelo desajustamento entre as prioridades nacionais e as ações políticas ao nível local (Dinica, 2006; Sofield \& $\mathrm{Li}, 2011$ ). Um outro risco associado relaciona-se com o facto de, em certos contextos, a descentralização do poder ser suscetível de provocar problemas - os 
grupos mais preparados podem aproveitar a dispersão de poder para fazer prevalecer os seus interesses (Yüksel et al., 2005).

Quanto às políticas públicas de promoção do desenvolvimento sustentável do turismo e suas implicações em termos de governance, podemos dizer que é uma das temáticas que os investigadores mais estudaram. Considerando-se que a implementação de uma estratégia de turismo sustentável requer a cooperação de um conjunto alargado e diferenciado de stakeholders - de autoridades públicas nacionais e locais a operadores de transporte, restauração, turistas, comunidades locais. Mas também a criação de redes e parcerias constituídas por atores públicos e privados, que possibilitem a formulação, comunicação, discussão, negociação e implementação, dos princípios para o desenvolvimento sustentável do turismo. Sem esquecer a necessidade de estas políticas públicas se sustentarem numa estratégia holística que mantenha a comunhão da visão e da estratégia no conjunto dos intervenientes (Caffyn \& Jobbins, 2003; Dinica, 2006, 2009; Dredge \& Whitford, 2011; Erkuş-Öztürk \& Eraydın, 2010; Hall, 2011a; Sofield \& Li, 2011; Vernon et al., 2005).

Ainda quanto à questão das políticas públicas de promoção da sustentabilidade, a análise dos artigos permitiu depreender a existência de duas formas principais de atuação do Estado. Uma mais próxima da lógica da governança, em que a sustentabilidade surge como objetivo político, daí o privilegiar de formas "manageriais" e tendencialmente centralizadas de atuação do Estado com base em "ordens" ou diretrizes. Enquanto na governação, a sustentabilidade, mais que um fim das políticas públicas seria uma característica de um processo: um modo de vida, um modelo de desenvolvimento assente na tradição e na diversidade cultural. Numa perspetiva assente na autenticidade das gentes e num longo prazo que tende à apreciação de normas e valores perenes que sustentam e regulam formas descentralizadas de governação que limitam a atuação do Estado: não confundindo a coisa "pública" ou "comum", com a "estatal". Acentuando, por isso, a responsabilidade de todos pelo que é comum, duradouro, próprio e verdadeiramente distintivo de um povo ou comunidade. Dando assim sentido e relevância a uma popular distinção de Glenn Greenwald: "Transparency is for those who carry out duties and exercise public power. Privacy is for everyone else".

A esta luz, percebe-se que, mesmo encarando de forma otimista a governance como uma nova forma do Estado atuar e resolver "velhos" problemas no turismo, possa ser criticada por não aumentar a participação democrática e a transparência dos processos de decisão e formulação das políticas públicas (Dredge \& Whitford, 2011). A razão para o surgimento de análises mais críticas e para a diminuição do entusiasmo inicial, prende-se com o facto de as estruturas institucionais, os processos de elaboração de políticas públicas e as estruturas de poder pré-existentes muitas vezes determinarem os resultados (Beaumont \& Dredge, 2010): a tal visão instrumental que não deixa 
de estar presente na chamada Nova Gestão Pública. Ajudando assim a explicar a tal possibilidade de os princípios da governance poderem ser mais retóricos do que efetivos (Dredge \& Whitford, 2011). O que ainda mais vem valorizar a importância de uma boa clarificação da oposição entre governação e governança. Distinção a que o termo em inglês - governance - não atende, impedindo-nos assim de ter em conta as razões por que a governance pode e deve ser entendida em sentidos opostos (Moreira, 2014). Razões que ajudariam ao melhor controlo dessa máquina de redução do público ao estatal: a governança. Fazendo-nos regressar ao sentido original da res-pública, com coisa pública ou comum: a governação. Sentido ainda presente em texto do século XV de Fernão Lopes - “... era (El-rei D. Pedro I) muito amado de seu poboo, por o manter em dereito, e justiça, desi boa governança que em seu Reino tinha" (Crónica de D. Pedro, cap. 4, 17, ed. de 1932). Dando à "governação" um significado idêntico ao da "boa governança" medieval: recuperando assim um sentido ainda não pervertido pelo espírito do mercantilismo. Precisão que obriga, hoje, a distinguir entre "Sociedade de Bem-estar" e "Estado de Bem-estar", indagando em que medida o poder político e administrativo, também no âmbito do turismo, deverá ser avaliado pelo que faz ou por tudo quanto não deixa ou impede de fazer?

\section{Resumo, discussão e conclusão}

O cruzamento da abordagem teórica com a análise dos artigos permitiunos perceber que a discussão da governance no turismo, sobretudo na análise das políticas públicas de turismo, tem ainda, até por ser recente, muitos aspetos a explorar. É importante referir que o presente estudo apresenta limitações recorreu apenas à base de dados Scopus para selecionar artigos, dos quais somente se analisaram 18 - que podem condicionar a apreciação da governance nas políticas públicas de turismo.

Os artigos analisados são fundamentalmente exploratórios e descritivos. Os métodos de recolha e análise de dados utilizados não permitem estabelecer relações de causalidade relativamente às implicações do movimento governance nas políticas públicas de turismo, pois são essencialmente qualitativos e os métodos quantitativos recorrem maioritariamente a estatísticas descritivas.

Nesta sequência podemos aferir que os estudos do turismo que se referem às implicações da governance nas políticas públicas necessitam de incluir metodologias mais quantitativas, o que permitirá identificar relações entre variáveis e validá-las cientificamente. Para além da inclusão de metodologias mais quantitativas é ainda necessário desenvolver estudos em torno de um conjunto de aspetos que carecem de investigação, tais como: (i) o estudo dos impactos da governance na atuação do Estado no turismo; (ii) verificação da 
existência de uma aplicação efetiva dos princípios da governance nas políticas públicas de turismo (ou se esta é apenas retórica); (iii) análise do contributo dos princípios da governance para o aumento da eficiência e eficácia das políticas públicas de turismo; (iv) realização de estudos que comparem um alargado número de países quanto à adoção dos princípios da governance nas políticas públicas de turismo, de forma a perceber a importância e influência dos contextos de cada país; (v) diversificação do estudo da governance nas políticas públicas de turismo, uma vez que a investigação tem incidido fundamentalmente nas políticas de desenvolvimento sustentável; (vi) apreciação da exequibilidade da aplicação geral dos princípios da governance na formulação e implementação das políticas públicas de turismo, do ponto de vista político, temporal e económico.

Embora o conceito de governance possa ter diferentes utilizações (que podem ser melhor entendidas quando se tem em conta a distinção entre governação e governança), o presente estudo procurou sobretudo nos artigos analisados contemplar as implicações da reforma do sector público provocada pelo movimento da governance nas políticas públicas de turismo. 0 entendimento da governance no turismo, enquanto movimento de reforma do sector público, é, em termos gerais, similar ao da ciência política. Os artigos analisados destacam como caracterizadores da influência da governance nas políticas públicas de turismo os seguintes elementos: (i) participação dos atores privados e da sociedade civil no processo de decisão e implementação; (ii) formação de redes e parceria público-privadas; (iii) acentuação da lógica bottomup e da descentralização do poder; (iv) maior abertura e transparência do processo político; (v) estimulo à competição e cooperação entre os atores do sector do turismo.

Caracterização que não está em oposição com os diferentes entendimentos considerados por Mark Bevir (Bevir, 2007, pp. 364-365). Um mais descritivo usando o termo governance para dar conta da mudança do papel do Estado decorrente das reformas do sector público nos anos 80 e 90 do século XX (como o uso de mercados, quase-mercados e redes na oferta de serviços públicos). Mudança de que se procurou dar conta com a Tabela 1 - síntese dos três paradigmas. Um segundo entendimento que olha para o Estado como muito (inter)dependente de outros poderes, podendo mesmo desempenhar só um pequeno (ou mesmo nenhum) papel: num quadro que, no limite aproxima a ideia de governação de uma visão otimista da autoridade resultante de uma cooperação humana voluntária capaz de assegurar ordem, mesmo com ausência do Estado. E, por fim, um terceiro entendimento, mais próximo da governança: privilegiando um tipo de Estado hierarquizado, como o existente antes das reformas do sector público dos anos 80 e 90 - ainda que, como vimos, o termo possa continuar a ter sentido quando nessas reformas a atuação do Estado é instrumental. 
Distinções que poderiam levar, erradamente, a sugerir o uso da expressão new governance para descrever as mudanças ocorridas no sector público a partir da última década do século XX. O que significaria que, por contraposição, 0 termo governance tenderia a expressar a atuação do Estado antes dessas mudanças. Deixando assim de fora o essencial, que, como vimos, tem a ver com distintas e opostas formas de relacionamento do Estado com a economia de mercado e a sociedade civil, que obrigam à diferenciação entre dois modelos de governo: a governação e a governança.

A esta luz, percebe-se que, não obstante aos reconhecidos méritos do movimento de governance, subsistam preocupações e desconfianças: o receio da governance ser um conjunto de princípios prescritivos de como governar, não sendo efetivamente aplicados pelos governos; o facto de certos contextos não estarem preparados para a lógica da governance, podendo, por exemplo, propiciar que certos grupos, devido aos seus recursos e poder, consigam manipular o processo político em favor dos seus interesses. Preocupações e desconfianças que, em parte, derivam das limitações linguísticas do inglês, não facilitarem a clara distinção entre duas formas de atuar do Estado/Governo.

Com base nos artigos analisados pode-se concluir que existe a ideia de que a reforma do sector público foi realizada por fases sucessivas, sendo a governação/governança a última fase desse processo. Entendimento oposto ao de Moreira e Alves (2010), onde a partir das três lógicas descritas Administração Pública Tradicional, Nova Gestão Pública e Governação Pública defendem que estas três vertentes orientadoras podem coexistir umas com as outras em algum grau em uma qualquer agência do Estado. Outro ponto que requereu esclarecimento e importa destacar tem a ver com a ideia de que a lógica de mercado e a formação de parcerias público-privadas nas políticas públicas, que tiveram o seu início com o movimento da Nova Gestão Pública, tanto podem ser enquadradas numa lógica de governança como de governação.

Ainda que, com base nos artigos considerados, se tenha de reconhecer que o entendimento da governance no turismo se aproxima mais da lógica da governança do que da lógica da governação. Daí ter-se optado no presente trabalho por utilizar o termo governance ou mesmo governança, sempre que a inclusão dos atores privados e da sociedade civil no processo político se dá por via de um Estado que, além de coordenador do processo político, assume a tarefa de definir as prioridades de desenvolvimento do turismo.

Cenário bem diferente será aquele em que, num contexto de governação, o Estado/Governo, mais que o papel de artesão, desempenha as funções de um jardineiro: de promoção, proteção e defesa de um ambiente e clima favoráveis ao fortalecimento do meio por via do estímulo à iniciativa e criatividade humana e valorização e sustentabilidade do nosso património cultural e natural. Num espírito de aliança entre tradição e inovação bem ilustrado por Vasco Graça Moura (2013, p. 40) com base num documento do Parlamento Europeu: "o 
conceito de sustentabilidade quando aplicado às nossas cidades e áreas rurais, significa o respeito por um conceito de autenticidade, a manutenção da diversidade, o reconhecimento da responsabilidade comum e visões e estratégias de longo prazo".

\section{Referências Bibliográficas}

Alves, André Azevedo., \& Moreira, José Manuel. (2004). O que é a Escolha Pública? Para uma análise económica da política. Cascais: Principia.

Andersson, Tommy D., \& Getz, Donald. (2009). “Tourism as a mixed industry: Differences between private, public and not-for-profit festivals". Tourism Management, 30(6), 847-856.

Bank, World. (1992). Governance and development. Washington, DC: The World Bank.

Beaumont, Narelle., \& Dredge, Dianne. (2010). “Local tourism governance: a comparison of three network approaches". Journal of Sustainable Tourism, 18(1), 7-28.

Bevir, Mark (Ed.) (2007). Encyclopedia of Governance (Vols. I). London: Sage Publications.

Bovaird, Tony. (2005). "Public Governance: balancing stakeholder power in a network society". International Review of Administrative Sciences, 71(2), 217228.

Bovaird, Tony, \& Löffler, Elke. (2003). Public Management and Governance. London: Routledge.

Caffyn, Alison., \& Jobbins, Guy. (2003). Governance Capacity and Stakeholder Interactions in the Development and Management of Coastal Tourism: Examples from Morocco and Tunisia. Journal of Sustainable Tourism, 11(2-3), 224-245.

Dinica, Valentina. (2006). Policy measures and governance for sustainable tourism and recreation in the Netherlands - An evaluation. Tourism, 54(3), 245-258.

Dinica, Valentina. (2009). "Governance for sustainable tourism: A comparison of international and Dutch visions". Journal of Sustainable Tourism, 17(5), 583603. 
Dredge, Dianne. (2006). "Policy networks and the local organisation of tourism". Tourism Management, 27(2), 269-280.

Dredge, Dianne., \& Whitford, Michelle. (2011). “Event tourism governance and the public sphere". Journal of Sustainable Tourism, 19(4-5), 479-499.

Erkuş-Öztürk, Hilal., \& Eraydın, Ayda. (2010). “Environmental governance for sustainable tourism development: Collaborative networks and organisation building in the Antalya tourism region". Tourism Management, 31(1), 113124.

Göymen, Korel. (2000). "Tourism and governance in Turkey". Annals of Tourism Research, 27(4), 1025-1048.

Hall, Colin Michael. (1999). “Rethinking collaboration and partnership: A public policy perspective". Journal of Sustainable Tourism, 7(3-4), 274-289.

Hall, Colin Michael. (2011a). "Policy learning and policy failure in sustainable tourism governance: from first- and second-order to third-order change?" Journal of Sustainable Tourism, 19(4-5), 649-671.

Hall, Colin Michael. (2011b). "A typology of governance and its implications for tourism policy analysis". Journal of Sustainable Tourism, 19(4-5), 437-457.

Hood, Cristopher. (1995). "The New Public Management in the 1980s: variations on a theme". Accounting, Organizations and Society, 20(2-3), 93-109.

Hood, Cristopher, \& Peters, Brainard Guy. (2004). "The Middle Aging of New Public Management: Into the Age of Paradox? " Journal of Public Administration Research and Theory, 14(3), 267-282.

Hughes, Owen E. (2003). Public Management \& Administration. New York: Palgrave Macmillan.

Kickert, Walter. (1997). "Public Governance in the Netherlands: an alternative to Anglo-American 'Managerialism'". Public Administration, 75(1), 731-752.

Kickert, Walter. (2002). "Public Governance in small Continental European States". International Journal of Public Administration, 25(12), 1471-1491.

Kooiman, Jan. (2003). Governing as Governance. London: Sage.

Le Grand, Julian. (2010). A Outra Mão Invisível: a oferta de serviços públicos em regime de concorrência. Lisboa: Actual Editora.

Madureira, César., \& Rodrigues, Miguel. (2006). “A Administração Pública do século XXI: aprendizagem organizacional, mudança comportamental e 
reforma administrativa". Comportamento Organizacional e Gestão, 12(2), 153-171.

Moreira, José Manuel. (2014). Governança e Governação: União Europeia, Liderança e Democracia. Nova Cidadania, 53, 43-49.

Moreira, José Manuel., \& Alves, André Azevedo. (2010). Gestão Pública e Teoria das Burocracias. Oeiras: INA Editora.

Moura, Vasco Graça. (2013). A Identidade Cultural Europeia. Lisboa: Fundação Francisco Manuel dos Santos.

O'Flynn, Janine. (2007). "From New Public Management to Public Value: paradigmatic change and managerial implications". The Australian Journal of Public Administration, 66(3), 353-366.

Peters, Brainard Guy. (2008). "The Napoleonic tradition. International". Journal of Public Sector Management, 21(2), 118-132.

Pierre, Jon., \& Peters, Brainard Guy. (2000). Governance, Politics and the State. London: MACMILLAN PRESS.

Plattner, Marc. (2013). Governação, Liderança e Democracia. Nova Cidadania, 51, 16-19.

Pollitt, Christopher. (2009). “Bureaucracies Remember, Post-Bureaucratic Organizations Forget? “ Public Administration, 87(2), 198-218.

Ruhanen, Lisa., Scott, Noel., Ritchie, Brent., \& Tkaczynski, Aaron. (2010). "Governance: a review and synthesis of the literature". Tourism Review, 65(4), 4-16.

Sofield, Trevor., \& Li, Sarah. (2011). "Tourism governance and sustainable national development in China: a macro-level synthesis". Journal of Sustainable Tourism, 19(4-5), 501-534.

Stoker, Gerry. (1998). "Governance as Theory: five propositions". International Social Science Journal, 50(1), 17-28.

Stoker, Gerry. (2008). "Gestão do Valor Público". A Administração Pública orientada para a missão. In José Manuel Moreira, Carlos Jalali \& André Azevedo Alves (Eds.), Estado, Sociedade Civil e Administração Pública: para um novo paradigma do serviço público.

Vernon, Jon., Essex, Stephen., Pinder, David., \& Curry, Kaja. (2005). "Collaborative policymaking: Local Sustainable Projects". Annals of Tourism Research, 32(2), 325-345. 
Villanueva, Luis F. Aguilar. (2006). Gobernanza e géstion Pública. México: Fondo de Cultura Económica.

Wang, Dan., \& Ap, John. (2013). "Factors affecting tourism policy implementation: A conceptual framework and a case study in China". Tourism Management, 36, 221-233.

Yüksel, Fisun., Bramwell, Bill., \& Yüksel, Atila. (2005). "Centralized and decentralized tourism governance in Turkey". Annals of Tourism Research, 32(4), 859-886.

Zahra, Anne Louise. (2011). "Rethinking regional tourism governance: the principle of subsidiarity". Journal of Sustainable Tourism, 19(4-5), 535-552. 